University of Nebraska - Lincoln

DigitalCommons@University of Nebraska - Lincoln

USDA National Wildlife Research Center - Staff

Publications

U.S. Department of Agriculture: Animal and Plant Health Inspection Service

2012

Detection probabilities of two introduced frogs in Hawaii: implications for assessing non-native species distributions

Christina A. Olson

Utah State University, christina.olson@aggiemail.usu.edu

Karen H. Beard

Utah State University, karen.beard@usu.edu

David N. Koons

Utah State University, david.koons@usu.edu

William C. Pitt

USDA/APHIS/Wildlife Services/National Wildlife Research Center, will.pitt@aphis.usda.gov

Follow this and additional works at: https://digitalcommons.unl.edu/icwdm_usdanwrc

Olson, Christina A.; Beard, Karen H.; Koons, David N.; and Pitt, William C., "Detection probabilities of two introduced frogs in Hawaii: implications for assessing non-native species distributions" (2012). USDA National Wildlife Research Center - Staff Publications. 1173.

https://digitalcommons.unl.edu/icwdm_usdanwrc/1173

This Article is brought to you for free and open access by the U.S. Department of Agriculture: Animal and Plant Health Inspection Service at DigitalCommons@University of Nebraska - Lincoln. It has been accepted for inclusion in USDA National Wildlife Research Center - Staff Publications by an authorized administrator of DigitalCommons@University of Nebraska - Lincoln. 


\title{
Detection probabilities of two introduced frogs in Hawaii: implications for assessing non-native species distributions
}

\author{
Christina A. Olson - Karen H. Beard • \\ David N. Koons • William C. Pitt
}

Received: 22 March 2011 / Accepted: 17 October 2011/Published online: 1 November 2011

(C) Springer Science+Business Media B.V. 2011

This article is a U.S. government work, and is not subject to copyright in the United States.

\begin{abstract}
Two nonnative Caribbean frogs, the Puerto Rican coqui and the Cuban greenhouse frog, recently invaded Hawaii. Because of its louder breeding call, management efforts have focused on the coqui, while little has been done to address the more cryptic greenhouse frog, even though it may be as widespread and have similar ecological impacts. The goal of this research was to determine the distribution and detection probability of both species on the island of Hawaii. We conducted a breeding call presence/absence survey at 446 sites every $2 \mathrm{~km}$ along major road networks. We re-surveyed 125 sites twice to determine detection and occupancy probabilities. Greenhouse frog detection probabilities $(0.24,0.29,0.48$, for each of the three visits, respectively) were lower than coqui detection probabilities $(0.58,0.73,0.50$, respectively) and increased with visits while those of the coqui did not. Greenhouse frog detection probabilities were lower in the presence of coquis for the first two surveys $(0.12$, $0.14)$ than in sites with greenhouse frogs alone (0.41), while greenhouse frogs had no effect on the detection of coquis. Site occupancy estimates for the greenhouse
\end{abstract}

C. A. Olson · K. H. Beard ( $₫)$. D. N. Koons Department of Wildland Resources and Ecology Center, Utah State University, Logan, UT 84322-5230, USA e-mail: karen.beard@usu.edu

W. C. Pitt

USDA/APHIS/Wildlife Services/National Wildlife

Research Center, Hawaii Field Station, Hilo, HI 96721, USA and coqui frog were 0.35 and 0.31 , respectively, suggesting the species are similarly widespread. Results suggest multiple visits to sites are required to detect the greenhouse frog. Furthermore, results suggest that accounting for detectability is essential when determining the extent of invasion of cryptic species.

Keywords Invasive - Coqui frog · Greenhouse frog · Amphibian · Hawaii · Occupancy modeling

\section{Introduction}

The ability to detect a species is critical in the assessment of species distribution (MacKenzie 2005; Mazerolle et al. 2007). Even if a site is well surveyed, a cryptic species may go overlooked or undetected by an investigator, and result in an underestimation of sites or habitat occupied (MacKenzie et al. 2006). In the case of nonnative species, detectability is important because it influences our understanding of the degree of invasiveness and our ability to manage the species (Christy et al. 2010). A cryptic invader presents several specific problems: (1) because early detection is difficult, it is more likely to become widespread and unmanageable; (2) it is likely to be more widespread than appreciated; and (3) it is more difficult to control because individuals are easily missed (Bomford and O'Brien 1995; Pitt and Witmer 2006). It is critical that we understand the detectability of nonnative species so that we conduct the appropriate level of monitoring. 
The greenhouse frog (Eleutherodactylus planirostris) invasion in Hawaii is an example of an invasive species that is likely widespread in the invaded range, but is difficult to detect because of its semi-fossorial, nocturnal habits and quiet breeding call (Goin 1947; Kraus and Campbell 2002; Raloff 2003), around 35-45 db at $0.5 \mathrm{~m}$ (Beard, unpublished data). On the other hand, the coqui frog (Eleutherodactylus coqui), which invaded Hawaii around the same time as the greenhouse frog (Kraus and Campbell 2002), provides an interesting contrast, because while it is a similar species, it has a much louder breeding call, up to 80-90 db at $0.5 \mathrm{~m}$ (Beard and Pitt 2005). The louder call has made the coqui invasion relatively easy to monitor, and the invasion has also been well studied and the target of a massive control effort (Beard et al. 2009). In contrast, the greenhouse frog invasion has been largely ignored (Olson et al. in press). Because the greenhouse frog is more cryptic than the coqui, there is a need to determine its distribution as well as its detectability in Hawaii.
Because both species have audible breeding calls, it is possible to conduct a presence/absence survey to determine their distribution patterns. Breeding call surveys are successful in determining amphibian species distributions when detection probabilities are high (>0.7) (Mazerolle et al. 2005; Pellet and Schmidt 2005; Brown 2007). Because detection probabilities of calling amphibians may be influenced by both environmental conditions (i.e. temperature) as well as observer ability to hear the call, particularly for species with quiet or cryptic (i.e. mimicry of other sounds, such as running water) calls (Weir et al. 2005; Mazerolle et al. 2007), environmental conditions and observer ability should be taken into account when conducting these types of studies. Furthermore, non-detection during a presence/absence survey does not necessarily mean that the species is not there (Fig. 1) and multiple visits to a site over a short time may be necessary to minimize "false" absences (MacKenzie et al. 2002).

We hypothesized that detection probabilities would be high for the coqui and low for the greenhouse frog
Fig. 1 During each survey each sample point is either (a) not occupied by the species or (b) occupied by the species. If the site is occupied, it may be either (c) detected by the observer or (d) not detected by the observer. Multiple visits to each sample point provide (e) an encounter history for each sample point, from which a detection probability of a species can then be calculated.

Encounter histories for both Eleutherodactylus coqui and E. planirostris are presented for the 125 study sites that were visited on all three surveys (a) 0

(b) 1

actual occurrence

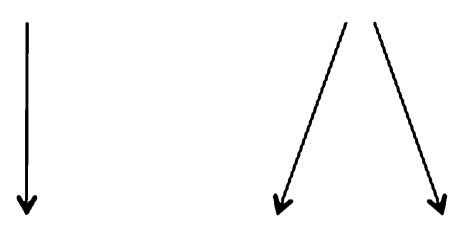

$\begin{array}{lll}0 & \text { (c) } 0 & \text { (d) } 1\end{array}$

observed occurrence

(e)

\begin{tabular}{|c|c|c|c|}
\hline $\begin{array}{l}\text { Encounter } \\
\text { history }\end{array}$ & Interpretation & $\begin{array}{c}\text { Number of } E . \\
\text { coqui sites }\end{array}$ & $\begin{array}{l}\text { Number of } E \text {. } \\
\text { planirostris sites }\end{array}$ \\
\hline 111 & $\begin{array}{l}\text { Observed (detected) } \\
\text { on all three surveys }\end{array}$ & 29 & 12 \\
\hline 100 & $\begin{array}{l}\text { Observed on first } \\
\text { survey only }\end{array}$ & 5 & 18 \\
\hline 010 & $\begin{array}{l}\text { Observed on second } \\
\text { survey only }\end{array}$ & 1 & 2 \\
\hline 001 & $\begin{array}{l}\text { Observed on third } \\
\text { survey only }\end{array}$ & 0 & 12 \\
\hline 110 & $\begin{array}{l}\text { Observed on first and } \\
\text { second survey }\end{array}$ & 7 & 6 \\
\hline 101 & $\begin{array}{l}\text { Observed on first and } \\
\text { third survey }\end{array}$ & 0 & 9 \\
\hline 011 & $\begin{array}{l}\text { Observed on second } \\
\text { and third survey }\end{array}$ & 5 & 2 \\
\hline 000 & $\begin{array}{c}\text { Not observed on any } \\
\text { survey }\end{array}$ & 78 & 64 \\
\hline
\end{tabular}


because the coqui has a louder call (Raloff 2003), but we hypothesized that overall site occupancy would be similar, given their same approximate time of introduction, similar pathway of introduction (nursery plants), and similar modes of spread (Kraus and Campbell 2002). Furthermore, because of the loudness of the coqui call, we hypothesized that the ability to detect the greenhouse frog would be lower in the presence of calling coqui, and that the ability to detect the coqui would be unaffected by the presence of calling greenhouse frogs. Although we expected that occupancy rates would be similar, we also hypothesized that the species were more likely to occur independently than at the same sites, because individuals of both species were randomly introduced to sites by either accidental or intentional means (Kraus and Campbell 2002; Peacock et al. 2009).

There are other variables that might influence our ability to detect these species, in addition to the difference in the loudness of their calls. For example, because both species increase breeding activity in warmer and wetter conditions (Goin 1947; Pough et al. 1983; Townsend and Stewart 1994; Meshaka and Layne 2005), we expected that higher air temperatures and relative humidity, lower wind speeds, and increased sky cover (i.e. from clear skies to rain) would increase the likelihood of call activity and detection (Weir et al. 2005). We also expected that the likelihood of these species occupying a site would be greater in lower elevation sites than higher elevation sites because most previously documented populations are in low elevations (Beard et al. 2009; Olson et al. in press). In addition, the mode of introduction and spread of both species, more specifically the sale and movement of nursery plants (Kraus and Campbell 2002) and vehicular traffic (Peacock et al. 2009), occur at a greater rate at low elevations where human population densities are greater. We thus included these covariates in our detection probability models to account for variability among sites.

The objectives of this study were three-fold: (1) to conduct an exploratory analysis with singlespecies occupancy models to determine the detection probability and occupancy rate of the coqui and the greenhouse frog independently across the island of Hawaii, (2) to determine if the ability to detect either species is influenced by the presence of the other species, and (3) to determine if the coqui and greenhouse frog co-occur in the same sites more often than expected by random chance.

\section{Methods}

Sampling design

The sampling design was created by selecting every other pixel of a $1 \mathrm{~km}$ grid overlaid on the island of Hawaii $\left(19^{\circ} 41^{\prime} 1^{\prime \prime} \mathrm{N}, 155^{\circ} 23^{\prime} 35^{\prime \prime} \mathrm{W}\right.$ at its center location), intersecting with the road network (as in Bisrat et al. in press). The road layer was obtained from the Hawaii Data Clearinghouse website (http://hawaii.wr.usgs.gov/hawaii/). This method was chosen because the design (1) increased the likelihood of sampling areas that are invaded because frogs in Hawaii are known to spread via vehicular traffic (Peacock et al. 2009), (2) increased our ability to sample many sites over a short period of time, and thus increase sample size, and (3) avoided spatial autocorrelation by creating a distance of more than $1 \mathrm{~km}$ between sites. However, because data were collected along the road network, evergreen forest and bare land cover types were underrepresented while grasslands, scrub/shrub, and cultivated land cover types were adequately represented in the dataset (Bisrat et al. in press). The design generated 464 points across the island but only 446 points were sampled due to limited access at some sites (Fig. 2). A Garmin eTrex Legend GPS handheld receiver (Garmin International, Inc, Olathe, KS) was used to geolocate sample points.

A subset of the 446 sample points was re-sampled over two additional survey periods for occupancy modeling. An ArcGIS extension (Hawth's Analysis Tools for ArcGIS; http://www.spatialecology.com/ htools/) was used to draw a random selection of 125 points for a stratified sub-sample, from each of the following four subgroups: (1) greenhouse frog presence only, (2) coqui presence only, (3) both species present, and (4) neither species present (classifications based on first survey). The 125 points for re-sampling consisted of 40 points with greenhouse frog presence only, 36 points with coqui presence only, 5 points with both species present, and 44 points with neither species present.

Coqui breeding activity increases during the rainy season in its native Puerto Rico (Townsend and Stewart 1994) and the greenhouse frog only breeds 


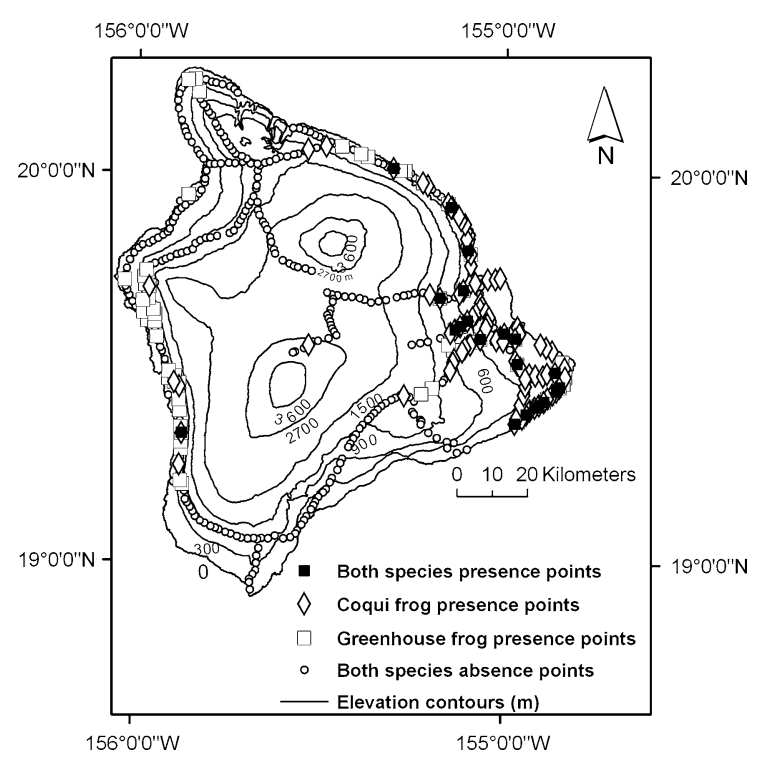

Fig. 2 Eleutherodactylus coqui and E. planirostris presence/ absence points on the island of Hawaii, USA. If a frog was detected during any survey, it was included as present. (Source: Elevation contours-http://hawaii.gov/dbedt/gis/)

during the rainy season in its native Cuba and its introduced range in Florida (Schwartz and Henderson 1991; Meshaka and Layne 2005). Rainfall occurs year-round on the eastern side of the island of Hawaii (Chu and Chen 2005), but the western side of the island is drier and experiences its maximum rainfall May to October (Kolivras and Comrie 2007). Because we were interested in sampling the entire island, surveys took place from May to July. The first survey occurred 02-15 May 2009, the second survey 06-10 July 2009, and the third survey 13-17 July 2009, beginning at 1900 hours and ending at 0200 hours, the peak calling hours for both species in their native ranges (Goin 1947; Woolbright 1985).

At each point, the observer walked $25 \mathrm{~m}$ off of the road, listened for $5 \mathrm{~min}$ and considered a site occupied by the greenhouse frog or the coqui frog by the detection of the male breeding call of either species. To avoid observer bias, presence was determined by the same researcher for each survey point. Even though coqui calls can be heard over $1000 \mathrm{~m}$, the greenhouse frog is only audible from a distance of $25 \mathrm{~m}$ (Olson, unpublished data). For consistency, coqui presence was only documented after the observer walked as close to the nearest calling coqui as required to confirm that the frog was within the radius of $25 \mathrm{~m}$ from the sample point. At each point, we also measured air temperature, relative humidity, and wind speed (maximum) using a portable weather device (Kestrel 3000, Kestrel Meters, MI), and estimated sky conditions using an ordinal classification code (0-clear skies, 1-broken/sky few clouds, 2-partly cloudy, 3-overcast, 4-drizzle, 5-rain).

Single-season, single species model

We used a single-season, single species model to conduct an exploratory analysis of occupancy estimates and detection probabilities for each frog species (see MacKenzie et al. 2002). This modeling is analogous to traditional closed-population capturerecapture methods, but uses the proportion of area (or sites) occupied as a state variable rather than individuals as in a population study. This requires visiting sites multiple times within a season where the target species is either detected, with probability $p$, or not detected. The goal is to estimate the probability of a species occurring at a site, $\Psi$, knowing the species is not always detected, even when present. In other words the naïve occupancy rate, Occ naive is the proportion of total sites where presence of a species was actually observed, where $\Psi_{i}=\frac{O c c_{\text {nave }}}{p_{i}}$. Elevation (ELEV) in Hawaii (Fig. 2) was included as a sitespecific covariate in determining $\Psi$ to account for site variability. Analysis was conducted in program Presence (Hines 2006).

We then developed models in a step-wise manner to account for factors that might lead to variation in detection probabilities. Model selection was based on the Akaike's Information Criteria adjusted for sample size $\left(\mathrm{AIC}_{c}\right)$ and if overdispersion was detected in the most parameterized model $(\hat{c}>1)$, the quasi-likelihood version was used $\left(\mathrm{QAIC}_{c}\right)$. High estimates of $p$ $(>0.7)$ were used to substantiate the ability to detect a species at a given site (Brown 2007).

We identified three factors that might lead to variation in detection probability: (1) timing of survey (time), (2) environmental variables, and (3) detection of co-species.

1. Time. We considered detection probabilities to be constant (.) or varying between the three surveys (t). Due to the duration of the surveys (e.g. 2 weeks for the first survey), we also considered (T) and quadratic $\left(\mathrm{T}^{2}\right)$ time trends in detection 
probability, coinciding with the day of the survey, 2 May 2009, delineated as Day 1.

2. Environmental variables. We explored the effect of four environmental covariates, air temperature (TEMP), relative humidity (RH), wind gust (WIND), and sky cover (SKY), on detection probabilities. To avoid problems with multicollinearity, we first determined that variables were independent and not correlated $\left(\mathrm{r}_{\text {spearman }}<|0.5|\right)$ using SAS v.9.1.3 for Windows (SAS Institute, Cary, North Carolina). We then explored additive models with all possible combinations of the four variables for a total of 15 possible models. If eliminating a covariate led to a reduction in $\mathrm{AIC}_{c}$ we discarded the higher order model from our model set, until no additional covariates could be eliminated without leading to an increase in $\mathrm{AIC}_{c}$ (as in Pagano and Arnold 2009). Complex models with one additional covariate and $\Delta \mathrm{AIC}_{c}<2$ were considered to have uninformative parameters and removed from the model set.

3. Detection of other species. Because we hypothesized that calling coqui frogs may influence our ability to detect greenhouse frogs, but not vice versa, we explored the effect of the detection of co-species in the top model (GHF for coquis, COQUI for greenhouse frogs). If the new model had a lower $\mathrm{AIC}_{c}$, all models were then evaluated with the co-species covariate (an additional 14 models). Models with the co-species covariate that had a $\Delta \mathrm{AIC}_{c}<2$ were discarded from the model set.

Single-season, two species model

We then used a single season, two-species model to estimate occupancy and detection probabilities for both frog species and to further evaluate whether the detection of each species was influenced by the detection of the other species. The two species model is similar to the single species model, but with added probabilistic calculated parameters that account for the detection of one species on the effect of detecting the other species, while also allowing for possible false absences in the detection of either species. Analysis was also conducted in program Presence to estimate the following parameters: $\Psi^{m}$, the probability a site is occupied by species $m$ regardless of occupancy status of the other species, $\rho_{j}^{m}$, the probability of detecting species $m$, on the $j$ th survey, given only species $m$ is present at the site, and $r_{j}^{m}$, the probability of detecting species $m$ during the $j$ th survey, given both species are present (see MacKenzie et al. 2004).

A benefit of using the two species model is the ability to explore species interactions using empirical model selection approaches with two additional species interaction parameters (or species interaction factors, SIF): $\varphi$, the ratio of how likely the species are to co-occur at a site compared to what would be expected under a hypothesis of independence, and $\delta$, an interaction factor for detection probabilities given co-occurrence. In our study, the occupancy interaction is expressed as $\varphi=\frac{\psi^{G r C o}}{\psi^{G r} \psi^{C o}}$, where $\psi^{G r C o}$ is the probability that the site is occupied by both greenhouse and coqui frogs. If $\varphi$ is $>1$, then the species tended to cooccur more often than expected if they were distributed independently. Similarly, $\delta=\frac{r^{G r C o}}{r^{G r} r_{r} \text { Co }}$, where $r^{G r C o}$ is the probability of detecting both species during a survey at a site where both species occur. If $\delta$ is $<1$, then it is likely that observers were less likely to detect one species if the other species was heard during the same survey.

We first modeled the occupancy parameters as a function of elevation (ELEV), and detection parameters as a function of the covariates found in the single species model that were most significant (from the top model results) for greenhouse frogs (SKY) and for coquis (RH and WIND), removing covariates in a stepwise process as in the single-species model method. We then examined if detection parameters varied by time with the top covariate model.

To explore our hypotheses about detection probabilities, the model was evaluated for $\rho=r$ and $\rho \neq r$ for both frog species. First, because the coqui has a louder call, we expected the coqui to have higher detection probabilities than the greenhouse frog $\left(\rho^{C o}>\rho^{G r}\right)$. Second, we expected that given the presence of the coqui, detection probabilities of the greenhouse frog would be lower in sites with the coqui $\left(r^{G r}<\rho^{G r}\right)$. Finally, to examine species interactions, models with and without $\varphi$ and $\delta$ were evaluated, for a total of 28 models included in the analysis. Due to the number of parameters in two-species modeling, complex models may be over-parameterized, (MacKenzie et al. 2006), and were removed from the analysis. The 
model with the lowest $\mathrm{AIC}_{c}$ was considered the top or best model of those examined. Detection probabilities were then extrapolated for estimates at sites that were not included in the occupancy modeling based on covariates from the top model (Fig. 3).

\section{Results}

Study sites

Elevation of study sites ranged from 13 to $3,386 \mathrm{~m}$, with a mean of $553 \pm 28$ (mean \pm SE presented throughout). Temperatures during data collection ranged from 4.9 to $29.5^{\circ} \mathrm{C}$, mean of $21.8 \pm 0.5$ across all sites for all three surveys. Relative humidity during data collection ranged from 57.1 to $100 \%$ mean of $88.2 \pm 1.6$. Wind gusts ranged from 0 to $54.9 \mathrm{kph}$, mean of $6.4 \pm 0.8$. Mean sky conditions was $1.9 \pm 0.1$.
Single-season, single species model

We detected coqui frogs at 89 out of the 446 study sites (20\%), with 21 of those sites (24\%) co-occupied with the greenhouse frog. Estimated occupancy probability was $0.31 \pm 0.04$ (Table 1). During the first survey, 83 out of the 446 sites ( $91.2 \%$ of total coqui sites) were positively identified with coqui frogs, six new sites from the subset of 125 study sites (6.6\% of total coqui sites) were identified on the second survey, and zero new sites were positively identified with coqui frogs on the third survey. Sites were mostly in lowland nonnative and native forests and agricultural lands on the eastern and southeastern sides of the island of Hawaii (Fig. 2). The highest elevation where coquis were detected was $737 \mathrm{~m}$.

Model selection results indicate that there was a time (t) effect in detection probability of the coqui (Table 2). Detection probabilities were highest for the second survey, and lowest for the third survey (Table 1), and ranged across all study sites from
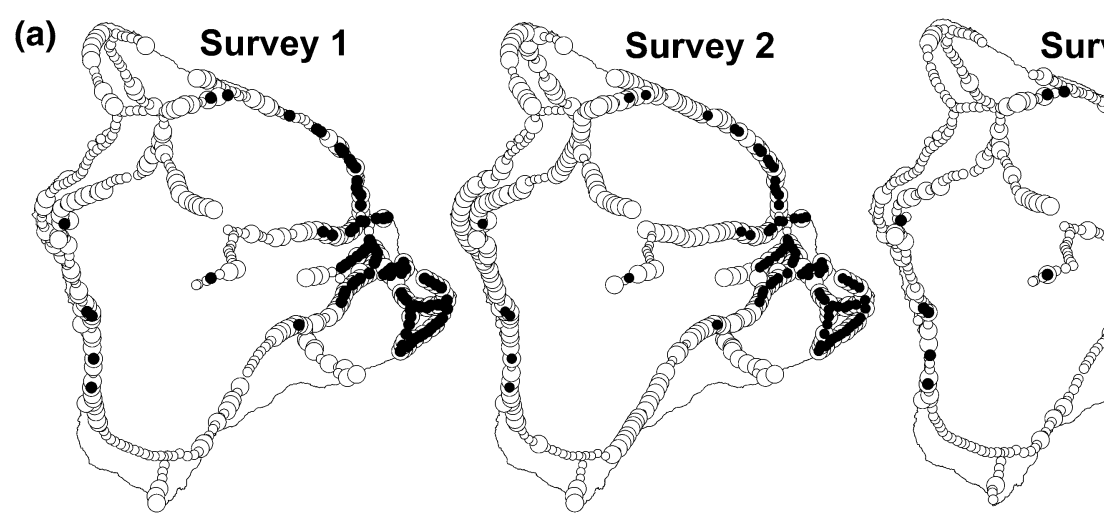

Survey 3
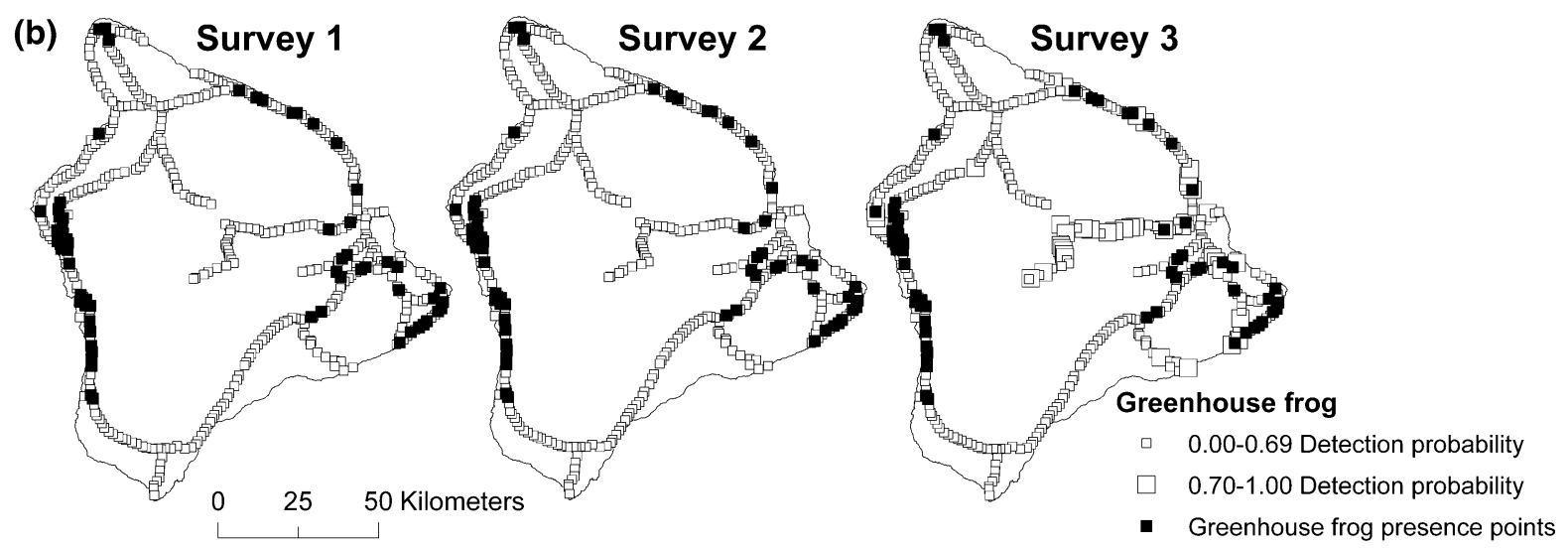

Fig. 3 Detection probabilities for each sample point based on the results from the three surveys for (a) Eleutherodactylus coqui and (b) E. planirostris on the island of Hawaii, USA 
Table 1 Mean individual covariate parameter estimates $( \pm \mathrm{SE})$ and $95 \%$ confidence intervals $(\mathrm{CI})$ from the top model (lowest $\mathrm{AIC}_{\mathrm{c}} /$ $\mathrm{QAIC}_{\mathrm{c}}$ ) of the single-season, single species models for the two Eleutherodactylus species, on the island of Hawaii, USA

\begin{tabular}{|c|c|c|c|c|}
\hline Parameter & E. coqui & $95 \% \mathrm{CI}$ & E. planirostris & $95 \% \mathrm{CI}$ \\
\hline Model & \multicolumn{2}{|c|}{ Model: $\Psi$ (ELEV), $p(\mathrm{t}+\mathrm{RH}+\mathrm{WIND})$} & \multicolumn{2}{|c|}{ Model: $\Psi$ (ELEV), $p(\mathrm{t}+\mathrm{SKY})$} \\
\hline Survey $1 p$ & $0.58(0.07)$ & $0.44,0.72$ & $0.24(0.05)$ & $0.15,0.36$ \\
\hline Survey $2 p$ & $0.73(0.08)$ & $0.56,0.89$ & $0.29(0.06)$ & $0.18,0.42$ \\
\hline Survey $3 p$ & $0.50(0.08)$ & $0.34,0.66$ & $0.48(0.07)$ & $0.33,0.62$ \\
\hline$\Psi$ & $0.31(0.04)$ & $0.23,0.39$ & $0.39(0.08)$ & $0.24,0.54$ \\
\hline
\end{tabular}

$0.0001 \pm 0.0002$ to $0.92 \pm 0.04$ for the first survey, $0.0001 \pm 0.0003$ to $0.97 \pm 0.02$ for the second survey, and $0.0001 \pm 0.0001$ to $0.87 \pm 0.05$ for the third survey. There were more sites with detection probabilities $>0.7$ for the coqui than for the greenhouse frog on all three surveys (Fig. 3).
All of the top models for coquis supported the inclusion of WIND as a covariate (Table 2). The probability of detection of coqui frogs decreased with higher wind speeds, increased slightly with higher relative humidity, and decreased with elevation. Variation in temperature, sky cover, and the detection

Table 2 Selection and fit statistics for the two Eleutherodactylus single-season single species models, and two species models on the island of Hawaii, USA

\begin{tabular}{|c|c|c|c|c|c|c|}
\hline Model & $\begin{array}{l}\mathrm{AIC}_{\mathrm{c}} / \\
\mathrm{QAIC}_{\mathrm{c}}\end{array}$ & $\Delta \mathrm{AIC}_{\mathrm{c}}$ & $w_{i}$ & $\begin{array}{l}\text { Model } \\
\text { likelihood }\end{array}$ & $\mathrm{K}$ & $\begin{array}{l}-2 \log \\
\text { (likelihood) }\end{array}$ \\
\hline \multicolumn{7}{|l|}{ Single species model: $E$. coqui } \\
\hline$\Psi(\mathrm{ELEV}), p(\mathrm{t}+\mathrm{RH}+\mathrm{WIND})$ & 464.17 & 0.00 & 0.60 & 1.00 & 7 & 449.91 \\
\hline$\Psi(\mathrm{ELEV}), p(\mathrm{t}+\mathrm{WIND})$ & 466.55 & 2.38 & 0.18 & 0.30 & 6 & 454.36 \\
\hline$\Psi($ ELEV $), p(\mathrm{t}+\mathrm{TEMP}+\mathrm{WIND}+\mathrm{SKY})$ & 467.33 & 3.16 & 0.12 & 0.21 & 8 & 451.00 \\
\hline$\Psi($ ELEV $), p(\mathrm{t}+\mathrm{TEMP}+\mathrm{WIND})$ & 467.88 & 3.71 & 0.09 & 0.16 & 7 & 453.62 \\
\hline$\Psi(\mathrm{ELEV}), p(\mathrm{t}+\mathrm{TEMP}+\mathrm{RH}+\mathrm{SKY})$ & 487.10 & 22.93 & 0.00 & 0.00 & 8 & 470.77 \\
\hline \multicolumn{7}{|l|}{ Single species model: E. planirostris } \\
\hline$\Psi(\mathrm{ELEV}), p(\mathrm{t}+\mathrm{SKY})$ & 452.84 & 0.00 & 0.59 & 1.00 & 6 & 497.93 \\
\hline$\Psi(\mathrm{ELEV}), p(\mathrm{t}+\mathrm{RH}+\mathrm{SKY})$ & 454.88 & 2.04 & 0.21 & 0.36 & 7 & 497.91 \\
\hline$\Psi(\mathrm{ELEV}), p(\mathrm{t}+\mathrm{TEMP}+\mathrm{WIND}+\mathrm{SKY})$ & 456.85 & 4.01 & 0.08 & 0.13 & 8 & 497.79 \\
\hline$\Psi(\mathrm{ELEV}), p(\mathrm{t}+\mathrm{RH}+\mathrm{WIND}+\mathrm{SKY})$ & 456.95 & 4.11 & 0.08 & 0.13 & 8 & 497.90 \\
\hline$\Psi(\mathrm{ELEV}), p(\mathrm{t}+\mathrm{TEMP}+\mathrm{RH}+\mathrm{WIND}+\mathrm{SKY})$ & 458.93 & 6.09 & 0.03 & 0.05 & 9 & 497.79 \\
\hline \multicolumn{7}{|l|}{ Two species model } \\
\hline$\Psi^{G r}, \Psi^{C o}, \varphi, p^{G r}(\mathrm{SKY}), p^{C o}(\mathrm{WIND})=r^{C o}(\mathrm{WIND}), r^{G r}(\mathrm{t}+\mathrm{SKY}), \delta$ & 1052.29 & 0.00 & 0.43 & 1.00 & 12 & 1027.57 \\
\hline$\Psi^{G r}, \Psi^{C o}, p^{G r}(\mathrm{t}+\mathrm{SKY}), p^{C o}(\mathrm{WIND})=r^{C o}(\mathrm{WIND}), r^{G r}(\mathrm{t}+\mathrm{SKY}), \delta$ & 1052.71 & 0.42 & 0.35 & 0.81 & 11 & 1030.10 \\
\hline$\Psi^{G r}, \Psi^{C o}, \varphi, p^{G r}(\mathrm{SKY}), p^{C o}(\mathrm{WIND})=r^{C o}(\mathrm{WIND}), r^{G r}(\mathrm{t}+\mathrm{SKY})$ & 1054.17 & 1.88 & 0.17 & 0.39 & 11 & 1031.56 \\
\hline$\Psi^{G r}, \Psi^{C o}, p^{G r}(\mathrm{t}+\mathrm{SKY}), p^{C o}(\mathrm{WIND})=r^{C o}(\mathrm{WIND}), r^{G r}(\mathrm{t}+\mathrm{SKY}), \delta(\mathrm{t})$ & 1056.56 & 4.27 & 0.05 & 0.12 & 14 & 1027.59 \\
\hline $\begin{array}{l}\Psi^{G r}, \Psi^{C o}, \varphi, p^{G r}(\mathrm{t}+\mathrm{SKY})=r^{G r}(\mathrm{t}+\mathrm{SKY}) \\
p^{C o}(\mathrm{WIND})=r^{C o}(\mathrm{WIND}), \delta\end{array}$ & 1065.69 & 13.40 & 0.00 & 0.00 & 10 & 1045.18 \\
\hline
\end{tabular}

Model selection was based on $\mathrm{AIC}_{\mathrm{c}}$ for $E$. coqui and $\mathrm{QAIC}_{\mathrm{c}}$ for $E$. planirostris $(\hat{\mathrm{c}}=1.13)$. Models with lowest $\Delta \mathrm{AIC}_{\mathrm{c}}$ are considered the best. Absence of $\varphi$ and $\delta$ in two species models implies no interaction in occupancy or detection probability (e.g., $\varphi=1$ and/or $\delta=1)$. ( $A I C_{c}$ small-sample size akaike information criterion, $w_{i}$ model weights, $K$ number of parameters, $C o=E$. coqui, $G r=$ E. planirostris) 
of the greenhouse frog had little effect on coqui detection probabilities.

We detected the greenhouse frog at 62 of the 446 study sites (14\%), with coquis detected at 21 of the greenhouse frog sites (34\%). Estimated occupancy probability was $0.39 \pm 0.08$ (Table 1 ). On the first survey, 46 out of the 446 sites $(75.4 \%$ of total greenhouse frog sites) were positively identified with greenhouse frogs, four new sites from the subset of $125(6.5 \%$ of total greenhouse frog sites) were identified on the second survey, and 12 new sites (19.6\% of total greenhouse frog sites) were identified on the third survey. Sites were mostly in lowland native shrublands and forests, nonnative forests, agricultural lands, and pasture lands on the southwestern and eastern sides of the island of Hawaii (Fig. 2). The highest elevation where greenhouse frogs were detected was $1,115 \mathrm{~m}$.

Model selection results indicate that detection probability for greenhouse frogs increased over time (Tables 1,2). Detection probabilities across all study sites ranged from $0.15 \pm 0.04$ to $0.60 \pm 0.12$ for the first survey, $0.18 \pm 0.05$ to $0.66 \pm 0.11$ for the second survey, and $0.34 \pm 0.07$ to $0.81 \pm 0.08$ for the third survey. Compared to the coqui, detection probabilities $>0.7$ only occurred at 37 sites for the greenhouse frog, and only on the third survey (Fig. 3).

The top 15 models for the greenhouse frog all included the SKY covariate (Table 2). The probability of detection of greenhouse frogs increased with increasing sky cover and decreased with elevation. Models with the covariate for coqui detection did not have a $\Delta \mathrm{AIC}_{c}<2$. Variation in relative humidity, temperature, and wind speed had little effect on detection of the greenhouse frog.

\section{Single-season, two species model}

Models that included a covariate ELEV for $\Psi^{\mathrm{Co}}$ and $\Psi^{G r}$ and the covariate $\mathrm{RH}$ for $p^{C o}$ and $r^{C o}$ were overparmeterized and removed from the model set. Models that included SKY for $p^{G r}$ and $r^{G r}$ and WIND for $p^{C o}$ and $r^{C o}$ were ranked higher than models without weather covariates (Table 2). Model selection results suggest that coquis and greenhouse frogs do not occur independently (Table 2), and that the species are more likely to co-occur at a study site than would be expected by random chance (Table 3). Model results also suggest that in addition to co-occurring at a site,
Table 3 Mean individual covariate parameter estimates $( \pm \mathrm{SE})$ and $95 \%$ confidence intervals (CI) from the top singleseason, two species model (lowest $\mathrm{AIC}_{\mathrm{c}}$ ) for the two Eleutherodactylus species on the island of Hawaii, USA

\begin{tabular}{|c|c|c|}
\hline \multirow{2}{*}{$\begin{array}{l}\text { Model: } \\
\text { Parameter }\end{array}$} & \multicolumn{2}{|c|}{$\begin{array}{l}\Psi^{G r}, \Psi^{C o}, \varphi, p^{G r}(\mathrm{SKY}), p^{C o}(\mathrm{WIND})= \\
r^{C o}(\mathrm{WIND}), r^{G r}(\mathrm{t}+\mathrm{SKY}), \delta\end{array}$} \\
\hline & Estimate & $95 \% \mathrm{CI}$ \\
\hline$\Psi^{G r}$ & $0.35(0.05)$ & $0.26,0.46$ \\
\hline$\Psi^{C o}$ & $0.31(0.03)$ & $0.24,0.38$ \\
\hline$\varphi$ & $1.36(0.24)$ & $1.28,2.57$ \\
\hline$p^{G r}$ & $0.41(0.06)$ & $0.29,0.53$ \\
\hline$p^{C o}$ & $0.69(0.05)$ & $0.59,0.79$ \\
\hline$r^{G r} 1$ & $0.12(0.06)$ & $0.01,0.23$ \\
\hline$r^{G r} 2$ & $0.14(0.08)$ & $0.04,0.38$ \\
\hline$r^{G r} 3$ & $0.67(0.15)$ & $0.38,0.96$ \\
\hline$r^{C o}$ & $0.69(0.05)$ & $0.59,0.79$ \\
\hline$\delta$ & $1.12(0.06)$ & $1.11,1.37$ \\
\hline
\end{tabular}

the two species were also more likely to be detected together by the observer than independently (Table 2). In addition, estimated occupancy rates for the greenhouse frog $(0.35 \pm 0.05)$ were not significantly different than estimated occupancy rates for the coqui $(0.31 \pm 0.03)$ (Table 3).

There was no time effect on the detection of the coqui in the two species model, and the probability of detecting the coqui when only the coqui was calling was equal to the probability of detecting the coqui when the greenhouse frog was calling $\left(p^{C o}=r^{C o}\right.$, Table 3). For the first two surveys, the probability of detecting the greenhouse frog was higher in sites where only the greenhouse frog was present than in sites where the coqui was detected, and greenhouse frog detection probabilities were lower than the coqui detection probabilities $\left(p^{G r}>r^{G r}\right.$, Table 3$)$. By the third survey, $95 \%$ confidence intervals suggest that there was an overlap in the detection probability of the greenhouse frog and coqui. Thus, detection probabilities for the coqui were higher and more consistent over all three surveys, while detection probabilities for the greenhouse frog were more variable.

Both the single-species and two-species models estimated occupancy probabilities slightly higher for the greenhouse frog than the coqui, and there is a greater discrepancy between naïve occupancy rates and estimated occupancy probabilities for the greenhouse frog than for the coqui because of the lower detection probabilities for the greenhouse frog. 


\section{Discussion}

We determined that detection probabilities from a breeding call survey differed between the two introduced Eleutherodactylus species on the island of Hawaii. As expected, detection probabilities for the greenhouse frog were low for the initial surveys and improved over time. Although coqui detection probabilities were higher than those for the greenhouse frog, probabilities varied amongst the three surveys, and were lower than expected $(<0.7)$ on the first and third survey. As expected, the ability to detect greenhouse frogs was lower in the presence of calling coquis while calling greenhouse frogs had no effect on the ability to detect the coqui.

In the single-species model, coqui detection probability did not increase over the three surveys; it was highest on the second survey and lowest on the third survey, which suggests that it was affected by individual site covariates during each survey. More specifically, sites with the lowest detection probabilities were also sites that had the lowest relative humidity and highest wind speeds. Other studies have found that coqui calls decline with humidity and higher wind speeds (Pough et al. 1983), and that calling is not influenced by temperature or cloud cover (Townsend and Stewart 1986). Because they call from mid-to-upper level forest canopies, they may be more exposed to dry conditions from increased wind speeds and low humidity than species, such as the greenhouse frog, that call from the forest floor (Pough et al. 1983). It should be noted that the two-species model was over-parameterized when we included a covariate for relative humidity on the detection of the coqui. It is possible that it was not captured in the two-species model due to the complexity of the model and the small effects of this parameter on coqui detection probability (MacKenzie et al. 2004). Sites with low detection probabilities on the second survey were in areas with the lowest predicted distribution potential of the coqui (Bisrat et al. in press).

For the greenhouse frog, unlike the coqui, detection improved by repeated visits to sites. As expected, detection probabilities were lower for the greenhouse frog than for the coqui, although not significantly so by the third survey. This may be because the observer learned to better detect the greenhouse frog over the duration of the study, or it may be because environmental conditions were more favorable for greenhouse frogs to call. More specifically, the rainy season for the western side of the island is from May to October (Kolivras and Comrie 2007), and the third survey took place in the middle of July. The increased detection probability for the greenhouse frog may indicate increased calling activity later in the rainy season. This hypothesis is supported by our results that detection probability increased with greater sky coverage (i.e. overcast skies and rain) and are consistent with other studies that suggest that greenhouse frogs increase calling activity during overcast skies and after recent rain (Goin 1947; Meshaka and Layne 2005). This may reflect that the greenhouse frog, unlike the coqui, is limited to breeding during certain times of the year in Hawaii. Finally, differences in detection probabilities may also result from differences in abundance, particularly if populations of greenhouse frogs are smaller than coqui populations at the sample sites (MacKenzie et al. 2006). We have no data on differences in densities at the sites.

The single and two-species models differed in the inclusion of the effect of coqui on greenhouse frog detectability. The effect of the presence of calling coqui on the detectability of the greenhouse frog was only slightly supported in the single-species model. This may be because in the single-species model, the covariate for presence of calling coqui does not account for false absences. In the two species model, greenhouse frog detection was lower in the presence of calling coqui. This was not unexpected because the coqui's louder call was thought to potentially mask the greenhouse frog's call. Results from both the single species and two species models support our hypothesis that the presence of the greenhouse frog did not have an effect on the detection of the coqui.

The estimated occupancy probabilities for both species overlap, and thus, are not different between the two species. In other words, the total number of sites occupied by the coqui and by the greenhouse frog on the island of Hawaii appears similar. However, there is a greater discrepancy between naïve occupancy rates and estimated occupancy probabilities for the greenhouse frog than for the coqui, and lower detection probabilities of the greenhouse frog contribute to this discrepancy (Bailey et al. 2009). Both the type of survey (audio) and timing of survey (only for one year) may have affected the results. In addition, even though we accounted for some variables that influence the ability to detect these species, there may be other 
factors influencing whether frogs were calling at the time of our visit to a study site. Because we cannot account for these factors, our occupancy estimates are likely conservative.

Elevation had a similar effect on the likelihood of sites being occupied by both species, which was expected given that both species were introduced to lowland sites and are likely to be limited by climatic conditions at high elevations (Kraus and Campbell 2002). Coquis have been found up to $1,200 \mathrm{~m}$ (Hawaii Invasive Species Council 2007), higher than our maximum elevation record for this study $(740 \mathrm{~m})$, and close to the maximum elevation of detected greenhouse frogs in this study $(1,100 \mathrm{~m})$. It is unknown if the frogs may be limited to areas below $1,200 \mathrm{~m}$ or if they have not yet spread to higher elevation sites (Rödder and Lötters 2010; Bisrat et al. in press).

The two-species model test of independence suggests that the coqui and greenhouse frog were more likely to be found at the same than different sites (MacKenzie et al. 2004). This contradicted our expectation that the distributions of these species would be independent (Kraus and Campbell 2002; Peacock et al. 2009). A possible explanation is their similar modes of spread, the sale and transport of nursery plants, and vehicular traffic (Kraus and Campbell 2002; Peacock et al. 2009). In addition, initial introductions may have been to the same areas: nurseries, plant retailers, and surrounding areas as well as roadsides, residential areas, and resorts. It is also possible that both the coqui and the greenhouse frog are now spreading to new sites via natural means, and that because there is some overlap in their preferred habitat, including human altered areas (Beard et al. 2009; Olson and Beard in press), they are more likely to co-occur.

Finally, statistically these species may co-occur more than expected for all 446 sample points because a large number of sites are unsuitable habitat for either species (Bisrat et al. in press). It is apparent from Fig. 2 that the coqui is predominantly found on the wet, eastern side of the island, while the greenhouse frog is found on the wet, eastern as well as the dry, western side. This may be because the greenhouse frog is better adapted than the coqui to the drier conditions and seasonal rain on the western side (Pough et al. 1977; Kolivras and Comrie 2007). However, many of these sites are in urban areas, such as landscaped gardens and agricultural sites, with human-mediated watering regimes. Another possible reason for the different distribution patterns is that control efforts may have limited the distribution of the coqui on the western side (Hawaii Invasive Species Council 2007).

This study did not assess the impacts of either species on Hawaiian ecosystems. Research has been conducted on the coqui's impacts (Sin et al. 2008; Beard 2007; Beard et al. 2008), but more studies are necessary to understand the effects of the greenhouse frog introduction. Both species predominantly consume leaf litter invertebrates (Beard 2007; Olson and Beard in press). The smaller greenhouse frog (mean SVL $17 \mathrm{~mm}$ for males, 22 for females) consumes more prey items per frog than the coqui (mean SVL $30 \mathrm{~mm}$ for males, 38 for females) (Beard et al. 2009; Olson and Beard in press), while densities of coquis may be higher (Woolbright et al. 2006; Beard et al. 2008; Olson et al. in press). Coquis have been shown to alter invertebrate communities and affect ecosystem processes, such as herbivory and leaf litter decomposition rates (Choi and Beard in press; Sin et al. 2008). It has been suggested that greenhouse frogs may have similar effects, but they have not been studied (Olson et al. in press).

This study was an initial investigation into the distribution of two introduced species of Caribbean Eleutherodactylus species on the island of Hawaii. Our study supports the idea that the coqui appears to be more widespread than the greenhouse frog due to the ease in detecting the coqui. Because detection of both species was $<1$, our study suggests that occupancy modeling is necessary to determine the distribution of the coqui and the greenhouse frog, using a form of replicated sampling with population closure (MacKenzie 2005). Our results emphasize the need to use early detection methods for invasives that are appropriate for detecting that species. Because the greenhouse frog appears to be widespread, we recommend that research be conducted to investigate its impacts ecologically to determine whether control efforts should also be aimed at this species.

Acknowledgments Support for this research came from the Jack H. Berryman Institute, USDA Wildlife Services Hilo Field Station, and the Ecology Center at Utah State University. We thank A. Huff for field assistance and T. Evans for comments on previous versions. Research was conducted under IACUC Protocol \#1402 and the following State of Hawaii permits: Injurious Wildlife Export, and DLNR/DSP Scientific Research, DLNR/DOFAW Access to Land and Native Invertebrate. 


\section{References}

Bailey LL, Reid JA, Forsman ED, Nichols JD (2009) Modeling co-occurrence of northern spotted and barred owls: accounting for detection probability differences. Biol Conserv 142:2983-2989

Beard KH (2007) Diet of the invasive frog, Eleutherodactylus coqui, in Hawaii. Copeia 2007:281-291

Beard KH, Pitt WC (2005) Potential consequences of the coqui frog invasion in Hawaii. Divers Distrib 11:427-433

Beard KH, Al-Chokhachy R, Tuttle NC, O’Neill EM (2008) Population density estimates and growth rates of Eleutherodactylus coqui in Hawaii. J Herpetol 42:626-636

Beard KH, Price EA, Pitt WC (2009) Biology and impacts of Pacific Island invasive species. 5. Eleutherodactylus coqui, the coqui frog (Anura: Leptodactylidae). Pac Sci 63:297-316

Bisrat, SA, White MA, Beard KH, and Cutler DR. (in press) Predicting the distribution potential of an invasive Puerto Rican frog (Eleutherodactylus coqui) in Hawaii using remote sensing data. Divers Distrib

Bomford M, O'Brien P (1995) Eradication or control for vertebrate pests? Wildl Soc Bull 23:249-255

Brown GW (2007) An evaluation of methods for assessing the population status of the threatened alpine treefrog Litoria verreauxii alpina in southeastern Australia. Copeia 2007:765-770

Choi R, Beard KH (in press) Coqui frog invasions change invertebrate communities in Hawaii. Biol Invasions. doi: 10.1007/s10530-011-0127-3

Christy MT, Adams AAY, Rodda GH, Savidge JA, Tyrrell CL (2010) Modelling detection probabilities to evaluate management and control tools for an invasive species. J Appl Ecol 47:106-113

Chu P-S, Chen H (2005) Interannual and interdecadal rainfall variations in the Hawaiian Islands. J Clim 18:4796-4813

Goin CJ (1947) Studies on the life history of Eleutherodactylus ricordii planirostris (Cope) in Florida: with special reference to the local distribution of an allelomorphic color pattern. University of Florida Press, Gainesville

Hawaii Invasive Species Council HISC (2007) Controlling the coqui. Retrieved from http://www.hawaiiinvasivespecies. org/hisc/enews/20070319hiscenews02_coqui.html

Hines JE (2006) PRESENCE2-software to estimate patch occupancy and related parameters. USGS-PWRC (<http:// www.mbr-pwrc.usgs.gov/software.html>)

Kolivras K, Comrie A (2007) Regionalization and variability of precipitation in Hawaii. Phys Geogr 28:76-96

Kraus F, Campbell EWI (2002) Human-mediated escalation of a formerly eradicable problem: the invasion of Caribbean frogs in the Hawaiian Islands. Biol Invasions 4:327-332

MacKenzie DI (2005) What are the issues with presenceabsence data for wildlife managers? J Wildl Manag 69: 849-860

MacKenzie DI, Nichols JD, Lachman GB, Droege S, Royle JA, Langtimm CA (2002) Estimating site occupancy rates when detection probabilities are less than one. Ecology 83:2248-2255

MacKenzie DI, Bailey LL, Nichols JD (2004) Investigating species co-occurrence patterns when species are detected imperfectly. J Anim Ecol 73:546-555
MacKenzie DI, Nichols JD, Royle JA, Pollock KH, Bailey LL, Hines JE (2006) Occupancy estimation and modeling: inferring patterns and dynamics of species occurrence. Academic Press, Boston

Mazerolle MJ, Desrochers A, Rochefort L (2005) Landscape characteristics influence pond occupancy by frogs after accounting for detectability. Ecol Appl 15:824-834

Mazerolle MJ, Bailey LL, Kendall WL, Royle JA, Converse SJ, Nichols JD (2007) Making great leaps forward: accounting for detectability in herpetological field studies. J Herpetol 41:672-689

Meshaka WE Jr, Layne JN (2005) Habitat relationships and seasonal activity of the greenhouse frog (Eleutherodactylus planirostris) in southern Florida. Fla Sci 68:35-43

Olson, CA, Beard KH (in press) Diet of the introduced greenhouse frog in Hawaii. Copeia

Olson, CA, Beard KH, Pitt WC (in press) Biology and impacts of Pacific Island invasive species: Eleutherodactylus planirostris, the greenhouse frog (Anura: Leptodactylidae). Pac Sci

Pagano AM, Arnold TW (2009) Estimating detection probabilities of waterfowl broods from ground-based surveys. J Wildl Manag 73:686-694

Peacock MM, Beard KH, O’Neill EM, Kirchoff VS, Peters MB (2009) Strong founder effects and low genetic diversity in introduced populations of coqui frogs. Mol Ecol 18: 3603-3615

Pellet J, Schmidt BR (2005) Monitoring distributions using call surveys: estimating site occupancy, detection probabilities and inferring absence. Biol Conserv 123:27-35

Pitt WC, Witmer GW (2006) Invasive predators: a synthesis of the past, present, and future. Internet Center for USDA National Wildlife Research Center, Staff Publications, Lincoln

Pough FH, Stewart MM, Thomas RG (1977) Physiological basis of habitat partitioning in Jamaican Eleutherodactylus. Oecologia 27:285-293

Pough FH, Taigen TL, Stewart MM, Brussard PF (1983) Behavioral modification of evaporative water loss by a Puerto Rican frog. Ecology 64:244-252

Raloff J (2003) Hawaii's hated frogs: tiny invaders raise a big ruckus. Sci News 163:11-13

Rödder D, Lötters S (2010) Explanative power of variables used in species distribution modelling: an issue of general model transferability or niche shift in the invasive greenhouse frog (Eleutherodactylus planirostris). Naturwissenschaften 97:781-796

Schwartz A, Henderson RW (1991) Amphibians and reptiles of the West Indies: descriptions, distributions, and natural history. University Press of Florida, Gainesville

Sin H, Beard KH, Pitt WC (2008) An invasive frog, Eleutherodactylus coqui, increases new leaf production and leaf litter decomposition rates through nutrient cycling in Hawaii. Biol Invasions 10:335-345

Townsend DS, Stewart MM (1986) The effect of temperature on direct development in a terrestrial-breeding, neotropical frog. Copeia 1986:520-523

Townsend DS, Stewart MM (1994) Reproductive ecology of the Puerto Rican frog, Eleutherodactylus coqui. J Herpetol 28:34-40 
Weir LA, Royle JA, Nanjappa P, Jung RE (2005) Modeling anuran detection and site occupancy on North American Amphibian Monitoring Program (NAAMP) routes in Maryland. J Herpetol 39:627-638

Woolbright LL (1985) Patterns of nocturnal movement and calling by the tropical frog Eleutherodactylus coqui. Herpetologica $14: 1-9$
Woolbright LL, Hara AH, Jacobsen CM, Mautz WJ, Benevides FL (2006) Population densities of the coqui, Eleutherodactylus coqui (Anura : Leptodactylidae) in newly invaded Hawaii and in native Puerto Rico. J Herpetol 40:122-126 